\title{
Optimization of supercritical dimethyl carbonate method for biodiesel production
}

$\operatorname{AUTHOR}(S)$ :

Ilham, Zul; Saka, Shiro

\section{CITATION:}

Itham, Zul ...[et al]. Optimization of supercritical dimethyl carbonate method for biodiesel production. Fuel 2012, 97: 670-677

ISSUE DATE:

2012-07

URL:

http://hdl.handle.net/2433/156174

\section{RIGHT:}

(C) 2012 Elsevier Ltd.; This is not the published version. Please cite only the published version.; この論文は出版社版でありません。引用の際に は出版社版をご確認ご利用ください。 


\section{Optimization of Supercritical Dimethyl Carbonate Method for Biodiesel Production} (1)

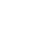

Zul Ilham and Shiro Saka*

Department of Socio-Environmental Energy Science, Graduate School of Energy Science, Kyoto University, Yoshida-honmachi, Sakyo-ku, Kyoto 606-8501, Japan

*Corresponding author: Tel/Fax: +81-75-753-4738; E-mail: saka@energy.kyoto-u.ac.jp (1)

Abstract: Biodiesel could be produced from triglycerides and dimethyl carbonate, instead of the conventional methanol, in this non-catalytic supercritical dimethyl carbonate method. It was demonstrated that, supercritical dimethyl carbonate method successfully converted triglycerides as well as fatty acids to fatty acid methyl esters (FAME) with glycerol carbonate, a higher value by-product compared to the conventional glycerol. The FAME are high in yield, comparable with supercritical methanol method, and satisfy the international standard for use as biodiesel fuel. In this study, therefore, optimization of supercritical dimethyl carbonate method was discussed to include all important key parameters such as reaction temperature, pressure, time, molar ratio of dimethyl carbonate to oil, the FAME yield, thermal decomposition, degree of denaturation, tocopherol content, oxidation stability and fuel properties. The optimum condition for supercritical dimethyl carbonate method was determined at $300^{\circ} \mathrm{C} / 20 \mathrm{MPa} / 20 \mathrm{~min} / 42: 1$ molar ratio of dimethyl carbonate to oil to have satisfactory yield of FAME at $97.4 \mathrm{wt} \%$. Conclusively, this study showed the importance to address all those key parameters in order to produce high quality biodiesel from supercritical dimethyl carbonate method.

Keywords: biodiesel; optimization; dimethyl carbonate; non-catalytic; supercritical process. 


\section{Introduction}

At present, homogenous alkali-catalytic transesterification process is the most common technology used in the industry to produce fatty acid methyl esters (FAME) or generally known as biodiesel, from refined vegetable oil and methanol [1]. This process requires high purity raw materials as feedstock, and separation of the catalyst from the biodiesel at the end of the process is inevitable.

Without pre-treatment, this method is not applicable for feedstock with high content of free fatty acids and water, such as the low-grade non-edible oils and waste cooking oils or fats [2]. The catalytic process also requires post-reaction separation of product, by-product and catalyst from the obtained two liquid phases. Most of the catalyst is normally found in the lower by-product layer of glycerol and, therefore, must be removed to produce pure glycerol [3,4]. As biodiesel production grows rapidly in recent years, the overproduction of crude glycerol as the by-product in this process has lead to an oversupply of glycerol in the market [5]. Thus, new non-catalytic production methods of biodiesel without producing glycerol are worth to be explored.

Transesterification under supercritical conditions as means to produce biodiesel in a non-catalytic manner has long been introduced with the establishment of the non-catalytic supercritical methanol method [6-11]. This introduction has triggered many further research works utilizing this method with wide range of raw materials or with certain improvements and modifications in the following years [12-17].

On this line of study, non-catalytic supercritical dimethyl carbonate method for biodiesel 
46

production has been developed previously in one-step [18] and two-step processes [19,20]. By-product such as glycerol carbonate from these processes was found to have higher value than glycerol that is produced in the conventional biodiesel production [18-21]. In addition, catalytic [22] and enzymatic routes [23-25] to produce biodiesel using dimethyl carbonate as reactant have also been studied by some other researchers.

However, it is very crucial to ensure that all the key parameters in the supercritical dimethyl carbonate are properly determined in order to optimize it. Many optimization studies were introduced for biodiesel production [26-28], particularly by non-catalytic supercritical methods, but most of those did not include and describe all important points to produce high quality biodiesel.

In this study, therefore, all important parameters for biodiesel production by non-catalytic supercritical dimethyl carbonate method have been discussed such as reaction temperature, pressure, time, molar ratio of dimethyl carbonate to oil, FAME yield, degree of denaturation, thermal decomposition, oxidation stability and fuel properties. Those key parameters were investigated to ensure that only high quality biodiesel, which fulfills the technical regulations and respects the engine technologies [29,30], could be produced by non-catalytic supercritical dimethyl carbonate method.

\section{Materials and Methods}

\subsection{Materials}

A commercial refined rapeseed oil supplied by Nacalai Tesque Inc. (Japan), whose fatty acid composition is presented in Table 1, was used in this study. GC analysis for the fatty acid composition 
65

was done in accordance to the Standard Method No. 2.3.1 and 2.4.2.1 [31]. Free fatty acid content of the oil was lower than $1 \mathrm{wt} \%$. Dimethyl carbonate $\left(\mathrm{Tc}=275^{\circ} \mathrm{C}, \mathrm{Pc}=4.63 \mathrm{MPa}\right)$ was used as the solvent and glycerol carbonate, glyoxal, various authentic compounds of oleins, methyl esters and fatty acids such as palmitic, stearic, oleic, linoleic, and linolenic acids were all obtained from Nacalai Tesque Inc. (Japan) and Wako Pure Chemical Industries Ltd. (Japan), all of which were of the highest purity available.

\subsection{Experimental Methods}

To study the effect of reaction temperature, pressure, time, molar ratio of dimethyl carbonate

to oil and thermal stability of FAME, the supercritical biomass conversion system developed previously in our laboratory which includes batch-type and flow-type were the ones utilized. For studies utilizing batch-type, a reaction vessel made of Inconel-625 was charged with dimethyl carbonate and rapeseed oil at various molar ratios and subsequently immersed in the molten tin bath heated at the designated range of temperature and pressure tested. After a fixed reaction time, it was transferred into the water bath to quench the reaction immediately.

In the flow-type reaction system, where temperature and pressure could be constantly controlled, tubular reaction vessel made from Hastelloy C-276 was used and the flow capacity of this system is up to $600 \mathrm{~mL} / \mathrm{h}$. The working temperature and pressure employed in this study ranged in $270-400^{\circ} \mathrm{C}$ and $10-40 \mathrm{MPa}$, respectively, all of which are monitored and controlled by thermocouple and pressure gauge. It should be noted, however, that all the results presented are the ones from 
84

flow-type system. Residence time was estimated by dividing the volume of the flow-type reaction vessel tube by the volumetric flow rate at the given conditions [31]. Batch-type was utilized only for initial and preliminary runs to check for the potential of the process. Details have been described in previous works [7-11]. Products from both steps were, then, analyzed by gel permeation chromatography (GPC) (GF-310HQ, 40 ${ }^{\circ} \mathrm{C}, 1 \mathrm{ml} / \mathrm{min}$, mobile phase: acetone, RID 10A) and high performance liquid chromatography (HPLC) (Cadenza CD-C18, $40^{\circ} \mathrm{C}, 1 \mathrm{ml} / \mathrm{min}$, mobile phase: methanol, RID 10A). Glycerol carbonate was analyzed by High Performance Liquid Chromatography (HPLC) (Column: Ultrahydrogel 120, oven temperature: $40^{\circ} \mathrm{C}$, flow: $1 \mathrm{~mL} / \mathrm{min}$, mobile phase: water, detector: RID 10A) while water content was measured by Karl-Fischer titration method in accordance to Standard Method No. 2.1.3.4 [32]. For the calibration curve of the authentic standard products, triolein, monoolein, diolein, glycerol carbonate and methyl oleate were used. All sets of experiments were made to at least triplicate for confirmation of the yields by utilizing 42:1 molar ratio of dimethyl carbonate to oil, although not treated statistically. The yield of FAME in weight percent as presented in this study refers to the percentage of yields conversion recovered based on theoretical yield.

\subsection{FT-IR Analysis to Detect Isomerization in Biodiesel}

As main components of biodiesel, five kinds of FAME (methyl palmitate (16:0), methyl stearate, (18:0), methyl oleate (18:1), methyl linoleate (18:2) and methyl linolenate (18:3)) were, respectively, exposed to supercritical dimethyl carbonate, as previously studied in supercritical methanol [33]. The unsaturated FAME used in this study have only cis-type double bonds since in nature, unsaturated 
103 fatty acids are all in cis-type only. The exposure was made by placing $100 \mathrm{mg}$ of the FAME in $4.9 \mathrm{~mL}$

104 of dimethyl carbonate using a $5 \mathrm{~mL}$ batch-type reaction vessel made of Inconel-625 at temperatures

105 between $270^{\circ} \mathrm{C}$ and $380^{\circ} \mathrm{C}$ with critical pressures higher than the critical pressure of dimethyl

106 carbonate $(\mathrm{Pc}=4.63 \mathrm{MPa})$ for a designated reaction time. The reaction vessel is equipped with gas

107 valve, in which air was substituted by $\mathrm{N}_{2}$ (>99.999\%) in advance utilizing the gas charging unit [31] to

108 ensure that the reaction pressure will be constantly at 20MPa during the reaction.

109

After the exposure, the obtained product was directly analyzed by HPLC, as described

110 beforehand. The remaining sample was then evaporated at $70^{\circ} \mathrm{C}$ for 30 min to remove dimethyl

111 carbonate on a rotary evaporator and analyzed by Fourier transform infrared (FT-IR) spectrometry

112 (Shimadzu, FT-IR 8300).

\subsection{Evaluation of Tocopherol Content}

The content of tocopherol in the biodiesel produced by supercritical dimethyl carbonate, as

one of the main natural antioxidants in vegetable oils [34], was also studied by the HPLC consisting of

the column (Asahipak ODP-50, $25 \mathrm{~cm}$ in length, $4.6 \mathrm{~mm}$ in inner diameter, Shodex Co.) and

Materials 2.4.10 and 2.5.2 [32].

\subsection{Evaluation of Fuel Properties}

FAME being produced were also subjected to various fuel properties tests to comply with 
Kinematic Viscosity Measuring System AKV-201 in accordance to ASTM D445. Carbon residue was

measured by Micro Carbon Residue Tester ACR-M3 in accordance to ASTM D4530. The pour point and cloud point were measured by a Mini Pour/Cloud Point Tester MPC-102 covering a range from

Filter Plugging Point Tester AFP-102 was used to measure cold filter plugging point in accordance to the European Standard Methods [36].

\section{Results and Discussion}

\subsection{Non-catalytic Supercritical Dimethyl Carbonate Method}

Saka [18], based on the direct transesterification of triglycerides with dimethyl carbonate at the 
141 method, by taking the difference in reaction pressure for supercritical methanol method at

$142350^{\circ} \mathrm{C} / 43 \mathrm{MPa}$ into consideration [7].

Additionally, to achieve a milder reaction condition, the two-step supercritical dimethyl

carbonate method has been explored [19-21]. Details on reaction schemes, by-products, advantages

study, a thorough outlook on all important key parameters to optimize non-catalytic supercritical

\subsection{Effect of Temperature and Pressure on FAME Yield}

because they allow the solvent properties of dimethyl carbonate to be adjusted [18]. Fig. 1 shows the

effect of temperature on FAME yield from triglycerides treated in supercritical dimethyl carbonate yield of FAME, respectively. 
Interestingly, such decomposition of dimethyl carbonate could not be detected at higher reaction

161

162

164

165

166

167

168

169

170

171

pressures. Concomitantly, high FAME yields could be obtained from reactions at high temperatures and pressures although longer treatment time (>30min) leads to thermal deterioration, shown in Figs. $1 \mathrm{c}$ and $1 \mathrm{~d}$. This decomposition phenomenon of dimethyl carbonate at lower reaction pressures is expected to be especially unique to supercritical dimethyl carbonate method due to the thermodynamic properties of dimethyl carbonate itself.

Anderson et al. [38] in their study showed that at low pressure condition (0.2MPa), dimethyl carbonate decomposes to carbon dioxide and methanol at reaction temperatures in a range between $127^{\circ} \mathrm{C}$ and $149^{\circ} \mathrm{C}$. To further investigate this alleged possible decomposition of dimethyl carbonate at low reaction pressure, it was subjected to high temperature $\left(\geq 270^{\circ} \mathrm{C}\right)$ and various pressures at supercritical condition, as presented in Fig. 2. It could be seen that dimethyl carbonate tends to decompose at lower reaction pressures (5MPa and 10MPa), while stable at higher pressures (20MPa and 40MPa), when treated for 30min. These findings were further supported by an earlier findings by Cross et al. [39], showing that dimethyl carbonate does not decompose at temperatures up to $390^{\circ} \mathrm{C}$, provided high pressure is employed. This phenomenon might be related to the cage effect of the solvent [40], explaining the enhancement of solvent reaction rate at high temperature and pressure.

The influence of reaction pressure on supercritical dimethyl carbonate method has also been investigated in Fig. 3. At a constant temperature of $300^{\circ} \mathrm{C}$, this variable was found to show a considerable impact on the reaction yield, especially if low reaction pressure was employed. The 
FAME yield was only $40 \mathrm{wt} \%$ at $5 \mathrm{MPa}$ and increased to $78 \mathrm{wt} \%$ at $10 \mathrm{MPa}$ after $30 \mathrm{~min}$ treatment. An additional pressure increases had a positive effect on the FAME yield to be more than $96 \mathrm{wt} \%$ for both 20MPa and 40MPa. However, as in Fig. 3, this is changed if the treatment time has been prolonged to be $60 \mathrm{~min}$ due to the thermal decomposition. Previous findings also supported this alleged statement [7-9]. These results presented beforehand showed the importance to describe temperature and pressure together in a specific reaction time for optimizing a supercritical process.

\subsection{Effect of Molar Ratios and Reaction Time on FAME Yield} required to react with 1 mole of triglycerides. In practice, however, excess amount of dimethyl 
operated at high temperature and high pressure with high molar ratio of dimethyl carbonate to reach the optimum yield in a short reaction time. The ideal range of reaction time for supercritical dimethyl

carbonate method is determined to be less than 30min as in Fig. 3 in order to prevent potential thermal

deterioration of the FAME.

\subsection{Thermal Stability of FAME in Supercritical Dimethyl Carbonate} recovered after a 30 min exposure. 
217 decomposition is seen to be worst. From these results, it was found that poly-unsaturated FAME are especially vulnerable to thermal decomposition when compared with mono-unsaturated and saturated ones. However, at the temperature of $300^{\circ} \mathrm{C} / 20 \mathrm{MPa}$ and preferably below, all FAME including the poly-unsaturated FAME were found to be stable as exposed to supercritical dimethyl carbonate method.

\subsection{Isomerization (Denaturation) of Unsaturated FAME}

223

Fig. 5 shows FT-IR spectra of various FAME treated in supercritical dimethyl carbonate method at different reaction conditions. As shown in Fig. 5a, without any treatment, there exists a

broad absorption peak for cis-type $\mathrm{C}=\mathrm{C}$ at wavenumber of $690 \mathrm{~cm}^{-1}$, representing the original condition for unsaturated FAME in nature. In Fig. 5b, although various FAME were treated at $300^{\circ} \mathrm{C} / 20 \mathrm{MPa}$ for $30 \mathrm{~min}$, no significant changes could be observed. Similar observation could be seen when FAME was treated at $270^{\circ} \mathrm{C} / 20 \mathrm{MPa}$ for $30 \mathrm{~min}$ (Data not presented). King [41], in his findings also showed no fatty acids isomerization at temperatures below $300{ }^{\circ} \mathrm{C}$.

232 FAME, while an absorption peak for trans-type $\mathrm{C}=\mathrm{C}$ appeared for methyl linoleate (18:2) and methyl linolenate (18:3). Data for $380^{\circ} \mathrm{C} / 20 \mathrm{MPa}$ is depicted in Fig. 5c. 
236

237

238

239

240

241

242

243

244

245

246

247

cis-isomer [42,43]. A difference between cis-type and trans-type methyl esters may be reflected in the cold flow properties. Therefore, the effect of cis- to trans- isomerization of FAME on its cold flow properties is important to be monitored, in order to prevent its denaturation [33].

\subsection{Tocopherol Content and Oxidation Stability}

As a main natural antioxidant in vegetable oils, the tocopherols play an important role in preventing oxidation in biodiesel. Rapeseed oil in its crude form contains mostly $\alpha$ - (5,7,8- trimethyl) and $\gamma$ - (7,8- dimethyl) tocopherol, with the latter almost doubled in amount and greater in its potential as antioxidant [44]. The significant decrease in tocopherol content could, thus, affect the oxidation stability of biodiesel, reducing its capability to be stored for a longer time [34]. While tocopherols remained almost unchanged at milder conditions of $270^{\circ} \mathrm{C} / 20 \mathrm{MPa}$ and $300^{\circ} \mathrm{C} / 20 \mathrm{MPa}$ as presented in Fig. 6, it decreased drastically at severe temperatures of $350^{\circ} \mathrm{C} / 20 \mathrm{MPa}$ and $400^{\circ} \mathrm{C} / 20 \mathrm{MPa}$, therefore, possibly deteriorating the oxidation stability of biodiesel in such high temperature conditions.

\subsection{Fuel Properties of FAME from Supercritical Dimethyl Carbonate Method}

To ensure that the FAME produced from supercritical dimethyl carbonate method are satisfactory as biodiesel, its fuel properties were studied, as presented in Table 2. The FAME were prepared from rapeseed oil treated in supercritical dimethyl carbonate method based on the optimized condition in this study $\left(300^{\circ} \mathrm{C} / 20 \mathrm{MPa} / 20 \mathrm{~min} / 42: 1\right.$ molar ratio of dimethyl carbonate to oil). The results were, then, compared with Japanese, EU and US standards [35-37]. Overall, the FAME from this method satisfied all requirements for international biodiesel standards except for the specification 
255

256

257

259

260

261

262

263

264

265

266

267

268

270

271

stated for oxidation stability. As mentioned earlier, oxidation stability is an important parameter to prevent deterioration and could be improved with addition of antioxidant or by utilizing oils with lower levels of unsaturated fatty acids [34].

In the supercritical process, it should also be noted that the FAME could be reduced in quality, especially if a reaction takes place at a very severe temperature under low reaction pressure, i.e., $380^{\circ} \mathrm{C} / 5 \mathrm{MPa}$. Problems in quality could be resulted from the physical and chemical properties of FAME itself as the major components of biodiesel, as well as minor fuel constituents arising due to poor transesterification condition [45]. This emphasizes the necessity to evaluate the biodiesel properties according to the international standards and to define a supercritical condition by stating both temperature and pressure of the reaction. In addition, it is crucial to monitor the temperature and pressure due to the marked effect of supercritical condition on the stability of dimethyl carbonate itself. If dimethyl carbonate subjected to high temperature and high pressure below or beyond the real optimum supercritical condition, dimethyl carbonate could decomposes as in Fig. 2 to reduce the yield of both FAME and value-added by-products [18-21].

Recently, there have been increasing numbers of publications in the area of biodiesel production via non-catalytic supercritical process [12-17]. Among them are optimization studies [26-28] including an optimization study of supercritical dimethyl carbonate based on minimum sets of experiments and response surface methodology, suggesting $380^{\circ} \mathrm{C}$ as optimum temperature without describing any pressure [28]. It should be noted that thermal stability of FAME in supercritical 
274 dimethyl carbonate is a major concern to produce high quality biodiesel. FAME including unsaturated members were stable in supercritical dimethyl carbonate at the range of $270^{\circ} \mathrm{C} / 20 \mathrm{MPa}$ to 276 $300^{\circ} \mathrm{C} / 20 \mathrm{MPa}$. However, at higher temperature and higher pressure, for example, $380^{\circ} \mathrm{C} / 20 \mathrm{MPa}$, they 277 palmitate, 16:0; methyl stearate 18:0). This is also in agreement with a previous study by Imahara et al.

[33]. Therefore, it is important that any optimization studies lead to practical applications due to the possible thermal decomposition and deterioration of biodiesel properties, especially if the reaction was preceded at high temperature with low reaction pressure.

\section{Conclusions \\ 4. Conclusions}

were partly decomposed thermally to reduce the FAME yield. It was apparent that the poly-unsaturated FAME (methyl linoleate, 18:2; methyl linolenate, 18:3) were also more vulnerable to thermal decomposition than the mono-unsaturated (methyl oleate, 18:1) and saturated esters (methyl

Based on these lines of evidence, this study stressed the importance to address all key parameters such as reaction temperature, pressure, time, molar ratio of dimethyl carbonate to oil, the FAME yield, degree of denaturation, thermal decomposition, oxidation stability and fuel properties towards optimization of supercritical dimethyl carbonate method for the production of high quality biodiesel. The optimum condition for supercritical dimethyl carbonate method is preferably in a controlled condition below $300^{\circ} \mathrm{C}$ and at high pressure more than $20 \mathrm{MPa}$, reaction time less than 30min to achieve a high yield of FAME at over $97 \mathrm{wt} \%$. Conclusively, this optimization study is very important to produce high quality biodiesel from supercritical dimethyl carbonate method.

\section{Acknowledgements}

This study is partially funded by the Japan Science and Technology Agency (JST) (July 2009 to March 2010), Kyoto University-University of Malaya AUN-SEED Net JICA Project and Global-COE Program "Energy Science in the Age of Global Warming”, Kyoto University (April 2008 
to March 2013), as well as Grant-in-Aid for Scientific Research "Challenging Exploratory Research" 298 (April 2011 to March 2013), supported by Ministry of Education, Culture, Sports, Science and Technology, Japan, for all of which the authors greatly acknowledge.

300

\section{References}

302

303

304

305

306

[1] Mittelbach M, Remschmidt C. Biodiesel: the comprehensive handbook. Vienna: Boersedruck Ges.m.b.H; 2004.

[2] Tomasevic AV, Siler-Marinkovic SS. Methanolysis of used frying oil. Fuel Process Technol 2003;81:1-6.

[3] Hajek M, Skopal F. Treatment of glycerol phase formed by biodiesel production. Bioresour Technol 2010;101:3242-5.

[4] Suppes GJ. Glycerol technology options for biodiesel industry. In: Knothe G, Krahl J, Van Gerpen J, editors. The Biodiesel Handbook, Urbana: AOCS Press; 2010, p. 439-55.

[5] Johnson DT, Taconi KA. The glycerin glut: Options for the value-added conversion of crude glycerol resulting from biodiesel production. Environ Prog 2007;26:338-48.

[6] Saka S. Applications of post-petrochemistry by supercritical fluid. Jasco Report 1999;3:28-31.

[7] Saka S, Kusdiana D. Biodiesel fuel from rapeseed oil as prepared in supercritical methanol. Fuel 2001;80:225-31.

[8] Kusdiana D, Saka S. Methyl esterification of free fatty acids of rapeseed oil as treated in supercritical methanol. J Chem Eng Japan 2001;34:383-7.

[9] Kusdiana D, Saka S. Kinetics of transesterification in rapeseed oil to biodiesel fuel as treated in supercritical methanol. Fuel 2001;80:693-8.

[10] Kusdiana D, Saka S. Two-step preparation for catalyst-free biodiesel fuel production. App Biochem Biotechnol 2004;115:781-91.

[11] Warabi Y, Kusdiana D, Saka S. Reactivity of triglycerides and fatty acids of rapeseed oil in supercritical alcohols. Bioresour Technol 2004;91:283-7. 
[12] Varma MN, Madras G. Synthesis of biodiesel from castor oil and linseed oil in supercritical fluids. Ind Eng Chem Res 2006;46:1-6.

[13] He H, Sun S, Wang T, Zhu S. Transesterification kinetics of soybean oil for production of biodiesel in supercritical methanol. J Am Oil Chem Soc 2007;84:399-404.

[14] Demirbas A. Studies on cottonseed oil biodiesel prepared in non-catalytic SCF conditions. Bioresour Technol 2008;99:1125-30.

[15] Tan KT, Lee KT, Mohamed AR. Production of FAME by palm oil transesterification via supercritical methanol technology. Biomass Bioenergy 2009;33:1096-9.

[16] Valle P, Velez A, Hegel P, Mabe G, Brignole EA. Biodiesel production using supercritical alcohols with a non-edible vegetable oil in a batch reactor. J Sup Flu 2010;54:61-70.

[17] Olivares-Carrillo P, Quesada-Medina J. Synthesis of biodiesel from soybean oil using supercritical methanol in a one-step catalyst-free process in batch reactor. J Sup Flu 2011;58:378-84.

[18] Ilham Z, Saka S. Dimethyl carbonate as potential reactant in non-catalytic biodiesel production by supercritical method. Bioresour Technol 2009;100:1793-6.

[19] Ilham Z, Saka S. Two-step supercritical dimethyl carbonate method for biodiesel production from Jatropha curcas oil. Bioresour Technol 2010;101:2735-40.

[20] Ilham Z, Saka S. Production of biodiesel with glycerol carbonate by non-catalytic supercritical dimethyl carbonate. Lipid Technol 2011;23:10-3.

[21] Ilham Z, Saka S. Glycerol to value-added glycerol carbonate in the two-step non-catalytic supercritical dimethyl carbonate method. In: Yao T, editor. Zero-Carbon Energy Kyoto 2010, Japan: Springer; 2011, p. 153-8.

[22] Fabbri D, Bevoni V, Notari M, Rivetti F. Properties of a potential biofuel obtained from soybean oil by transmethylation with dimethyl carbonate. Fuel 2007;86:690-7.

[23] Su EZ, Zhang MJ, Zhang JG, Gao JF, Wei DZ. Lipase-catalyzed irreversible transesterification of vegetable oils for fatty acid methyl esters production with dimethyl carbonate as the acyl acceptor. 
Biochem Eng J 2007;36:167-73.

350

351

352

353

354

355

356

[24] Tian X, Zhou B, Li X. Synthesis of biodiesel from cottonseed oil and dimethyl carbonate catalyzed by immobilized lipase. Petrochem Technol 2009;38:677-81.

[25] Zhang L, Sun S, Xin Z, Sheng B, Liu Q. Synthesis and component confirmation of biodiesel from palm oil and dimethyl carbonate catalyzed by immobilized-lipase in solvent-free system. Fuel 2010;89:3960-5.

[26] Patil PD, Gude VG, Mannarswamy A, Deng S, Cooke P, Munson-McGee S, et al. Optimization of direct conversion of wet algae to biodiesel under supercritical methanol conditions. Bioresour Technol 2011;102:118-22.

[27] Sawangkeaw R, Bunyakiat K, Ngamprasertsith S. Continuous production of biodiesel with supercritical methanol: Optimization of a scale-up plug flow reactor by response surface methodology. Fuel Process Technol 2011;92:2285-92.

[28] Tan KT, Lee KT, Mohamed AR. Optimization of supercritical dimethyl carbonate (SCDMC) technology for the production of biodiesel and value-added glycerol carbonate. Fuel 2010;89:3833-39.

[29] Fazal MA, Haseeb ASMA, Masjuki HH. Biodiesel feasibility study: An evaluation of material compatibility; performance; emission and engine durability. Renew Sustain Energy Rev 2011;15:1314-24.

[30] Tat M, Wang P, Van Gerpen J, Clemente T. Exhaust emissions from an engine fueled with biodiesel from high-oleic soybeans. J Am Oil Chem Soc 2007;84:865-9.

[31] Imahara $\mathrm{H}$, Xin J, Saka S. Effect of $\mathrm{CO}_{2} / \mathrm{N}_{2}$ addition to supercritical methanol on reactivities and fuel qualities in biodiesel production. Fuel 2009;88:1329-32.

[32] JOCS. Standard methods for fats, oils and related material (in Japanese). Japan: Japan Oil Chemists' Society; 1996.

[33] Imahara H, Minami E, Hari S, Saka S. Thermal stability of biodiesel in supercritical methanol. Fuel 2008;87:1-6. 
375 [34] Xin J, Imahara H, Saka S. Oxidation stability of biodiesel fuel as prepared by supercritical methanol. Fuel 2008;87:1807-13.

377

378

379

380

381

382

[35] ASTM. Standard test methods for D445, D4530, D2500, D6371, D93, D6749 and D6751 standards. West Conshoshocken: American Society for Testing and Materials; 2007.

[36] CEN. Standard test methods for EN14412, EN14105, ENISO12937, EN14104, EN14111 and EN14214. EU: European Committee of Standardization; 2003.

[37] JIS. Fatty acid methyl esters (FAME) standards for use as automotive fuel (In Japanese)-JIS K2390. Japan: Japan Industrial Standard Committee; 2008.

[38] Anderson SA, Manthata S, Root TW. The decomposition of dimethyl carbonate over copper zeolite catalyst. App Catal A: General 2005;280:117-24.

[39] Cross JTD, Hunter R, Stimson R. The thermal decomposition of simple carbonate esters. Aust J Chem 1976;29:1477-81.

[40] Turro NJ. Molecular structure as a blueprint for supramolecular structure chemistry in confined spaces. Proc Nat Aca Sci 2005;102:10766-70.

[41] King JW. Critical fluid technology for the processing of lipid-related natural products, Comptes Rendus Chimie 2004;7:647-59.

[42] Musavi A, Cizmeci M, Tekin A, Kayahan M. Effects of hydrogenation parameters on trans isomer formation, selectivity and melting properties of fat. Eur $\mathrm{J}$ Lipid Sci Technol 2008;110:254-60.

[43] Valenzuela A, Morgado N. Trans fatty isomers in human health and in the food industry. Biol Res 1999;32:273-87.

[44] Gunstone F. Vegetable oils. In: Shahidi F, editor. Bailey's Industrial Oil and Fat Products, New York: John Wiley and Sons Inc; 2005, p. 217-8.

[45] Knothe G. Improving biodiesel fuel properties by modifying fatty ester composition. Energy Environ Scie 2009;2:759-66. 


\section{Figure captions:}

402

403

Fig. 1 Effect of temperature on FAME yield from triglycerides treated in supercritical dimethyl

404

carbonate method at different reaction pressures

405

406

Fig. 2 Effect of various temperatures and pressures at supercritical conditions to dimethyl carbonate as a solvent after $30 \mathrm{~min}$ treatment

408

Fig. 3 Effect of pressure on FAME yield from triglycerides treated in supercritical dimethyl carbonate method at $300^{\circ} \mathrm{C}$

Fig. 4 Thermal stability of various FAME in supercritical dimethyl carbonate method under different temperatures at $20 \mathrm{MPa}$

414

Fig. 5 FT-IR spectra of various FAME as treated in supercritical dimethyl carbonate method at different reaction conditions a) Untreated FAME, b) $300^{\circ} \mathrm{C} / 20 \mathrm{MPa} / 30 \mathrm{~min}$ and c) $380^{\circ} \mathrm{C} / 20 \mathrm{MPa} / 30 \mathrm{~min}$

418 Fig. 6 Effect of temperature on tocopherol content in supercritical dimethyl carbonate method at 
a) $5 \mathrm{MPa}$

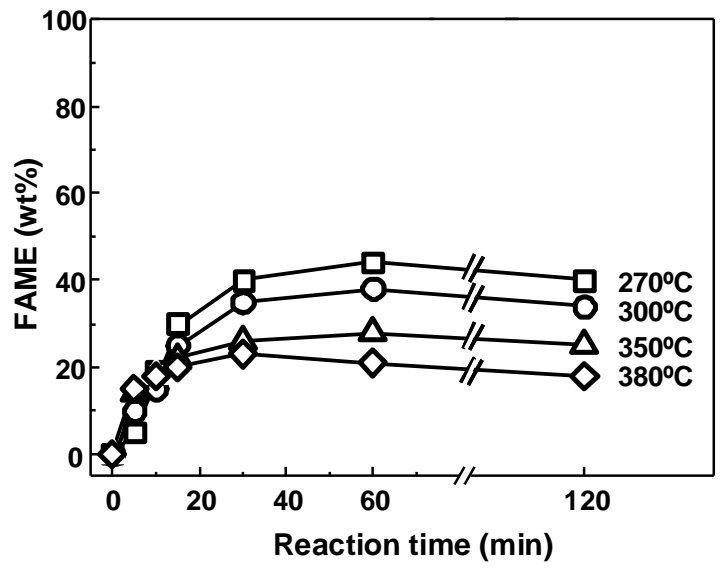

c) $20 \mathrm{MPa}$

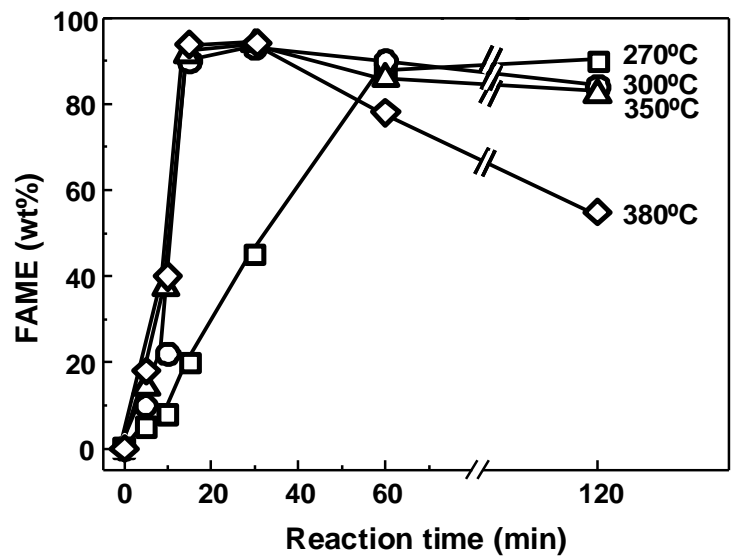

b) $10 \mathrm{MPa}$

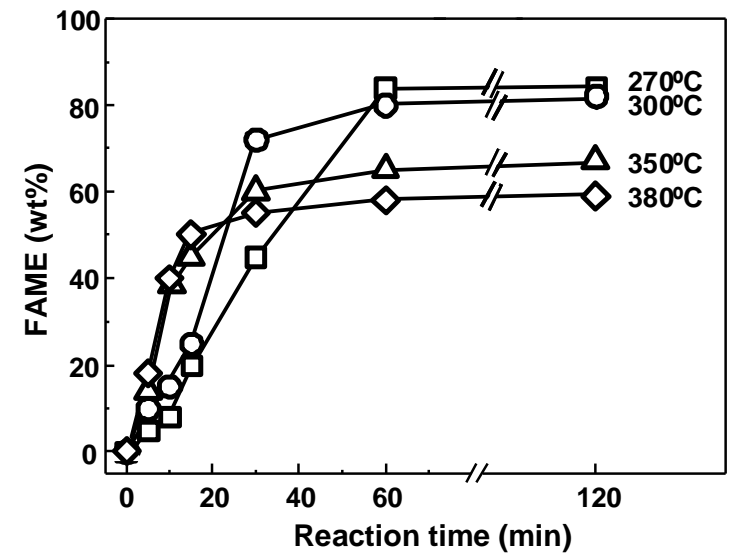

d) $40 \mathrm{MPa}$

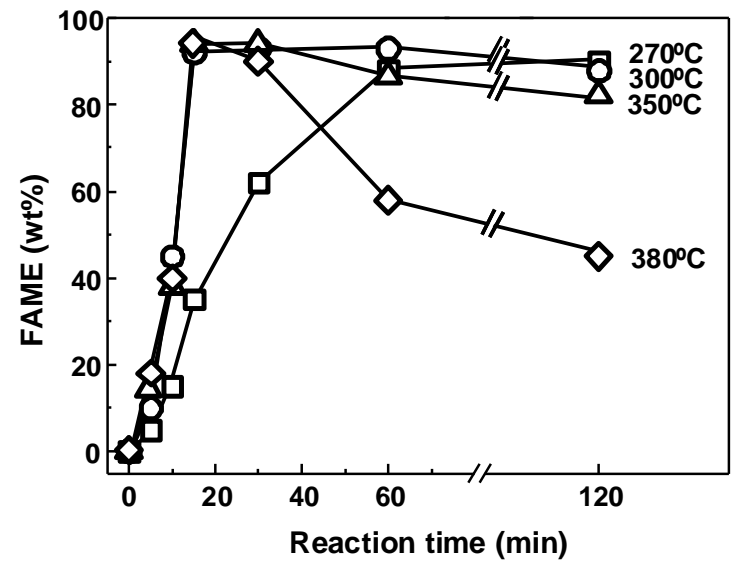

Fig. 1 Effect of temperature on FAME yield from triglycerides treated in supercritical dimethyl carbonate method at different reaction pressures 


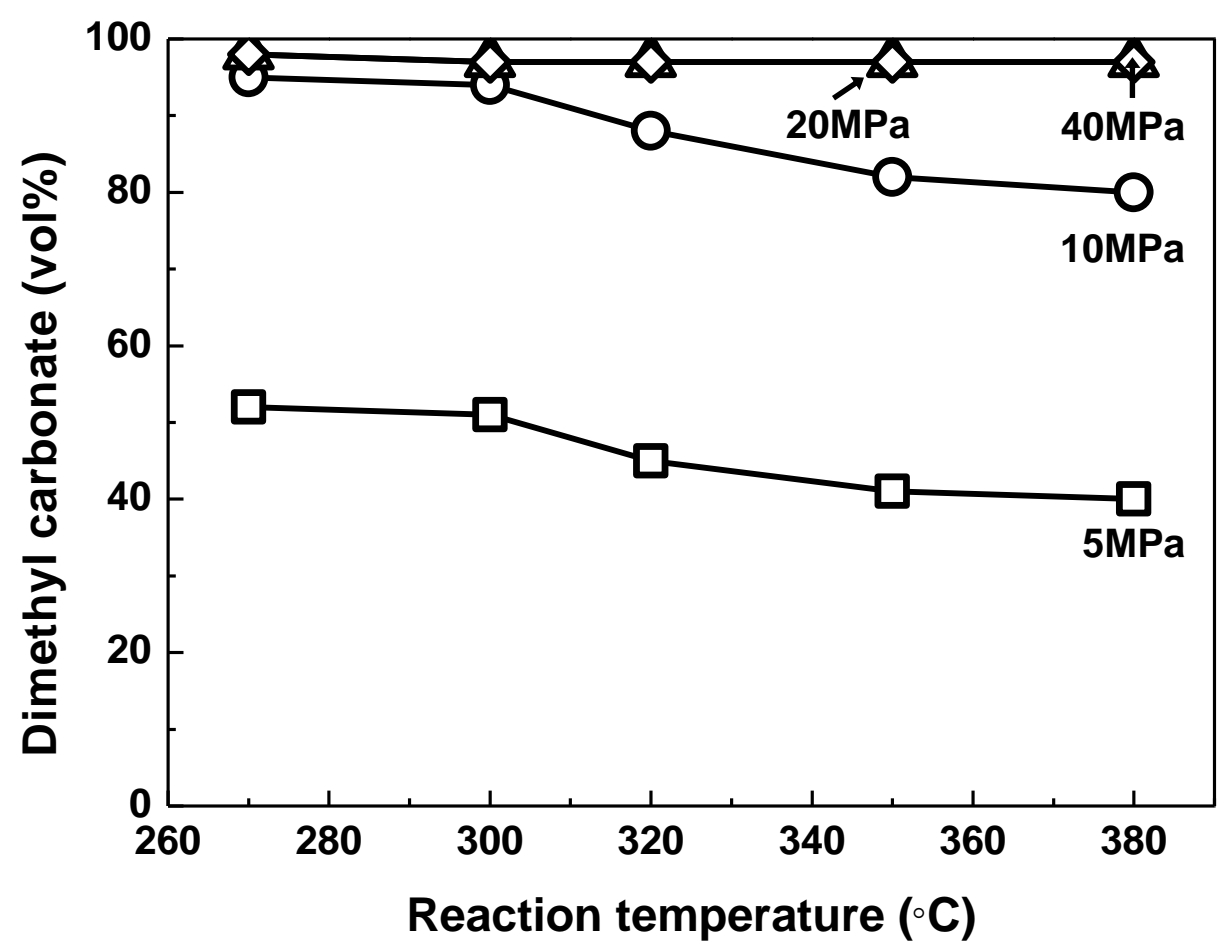

Fig. 2 Effect of various temperatures and pressures at supercritical conditions to dimethyl carbonate as a solvent after $30 \mathrm{~min}$ treatment 


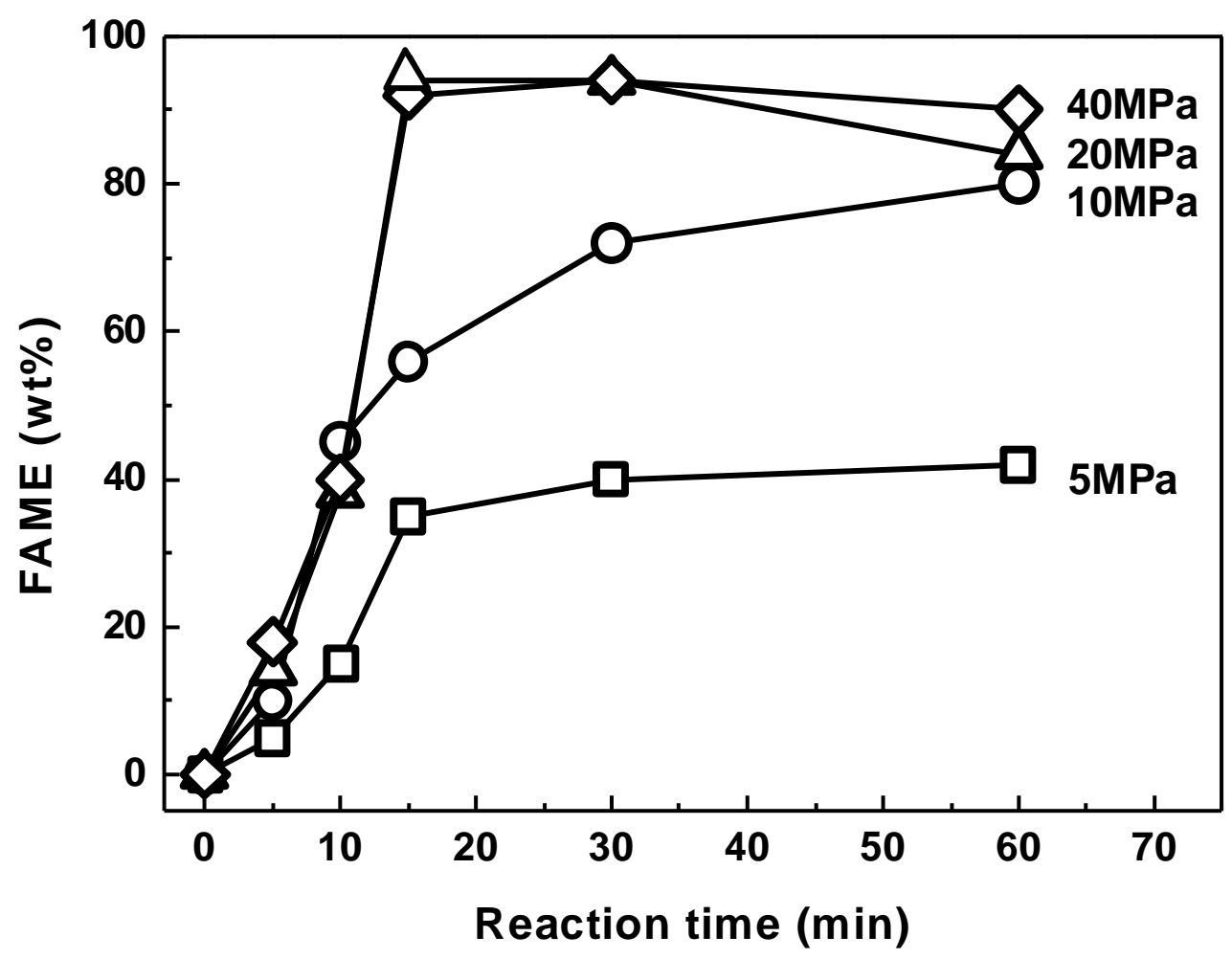

Fig. 3 Effect of pressure on FAME yield from triglycerides treated in supercritical dimethyl carbonate method at $300^{\circ} \mathrm{C}$ 
a) Methyl palmitate (16:0)

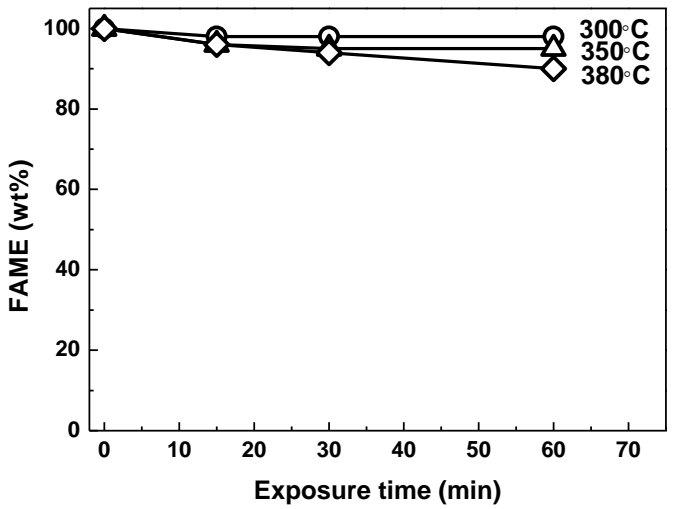

c) Methyl oleate (18:1)

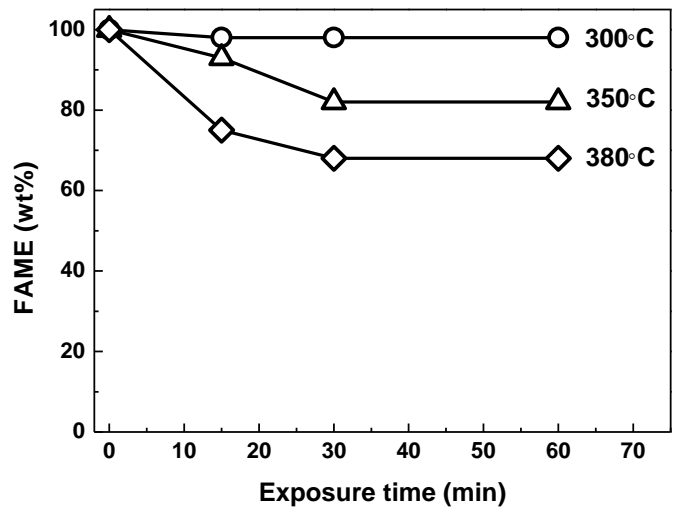

b) Methyl stearate (18:0)

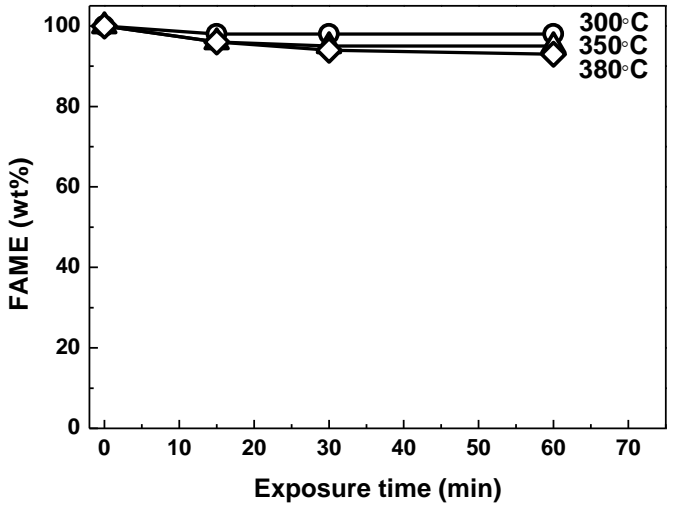

d) Methyl linoleate (18:2)

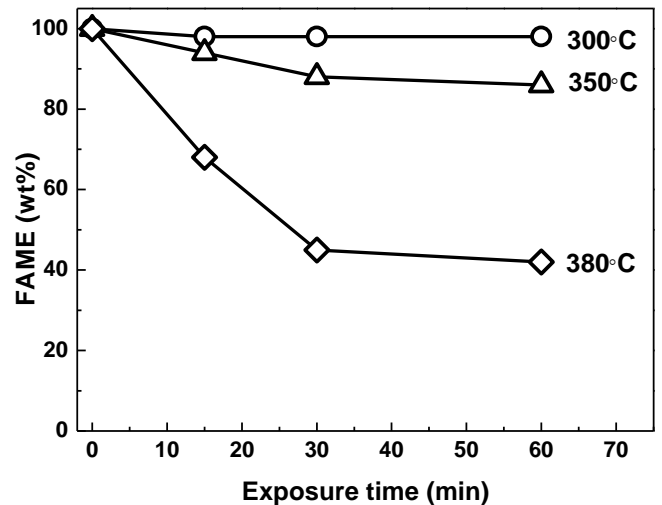

e) Methyl linolenate (18:3)

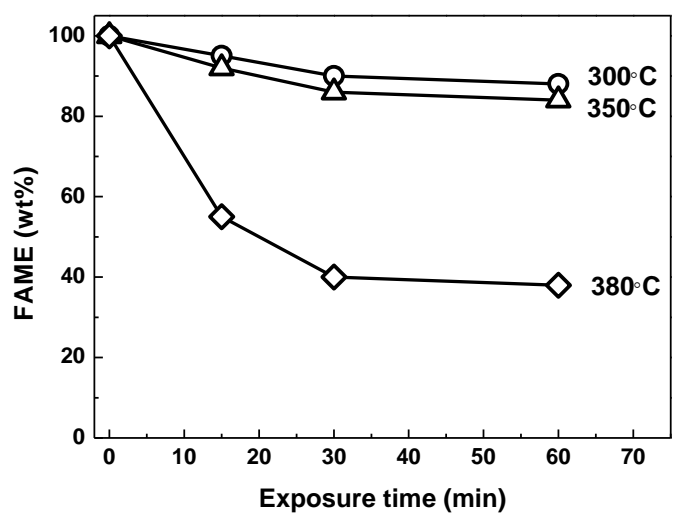

Fig. 4 Thermal stability of various FAME in supercritical dimethyl carbonate method under different temperatures at $20 \mathrm{MPa}$ 
a) Untreated FAME

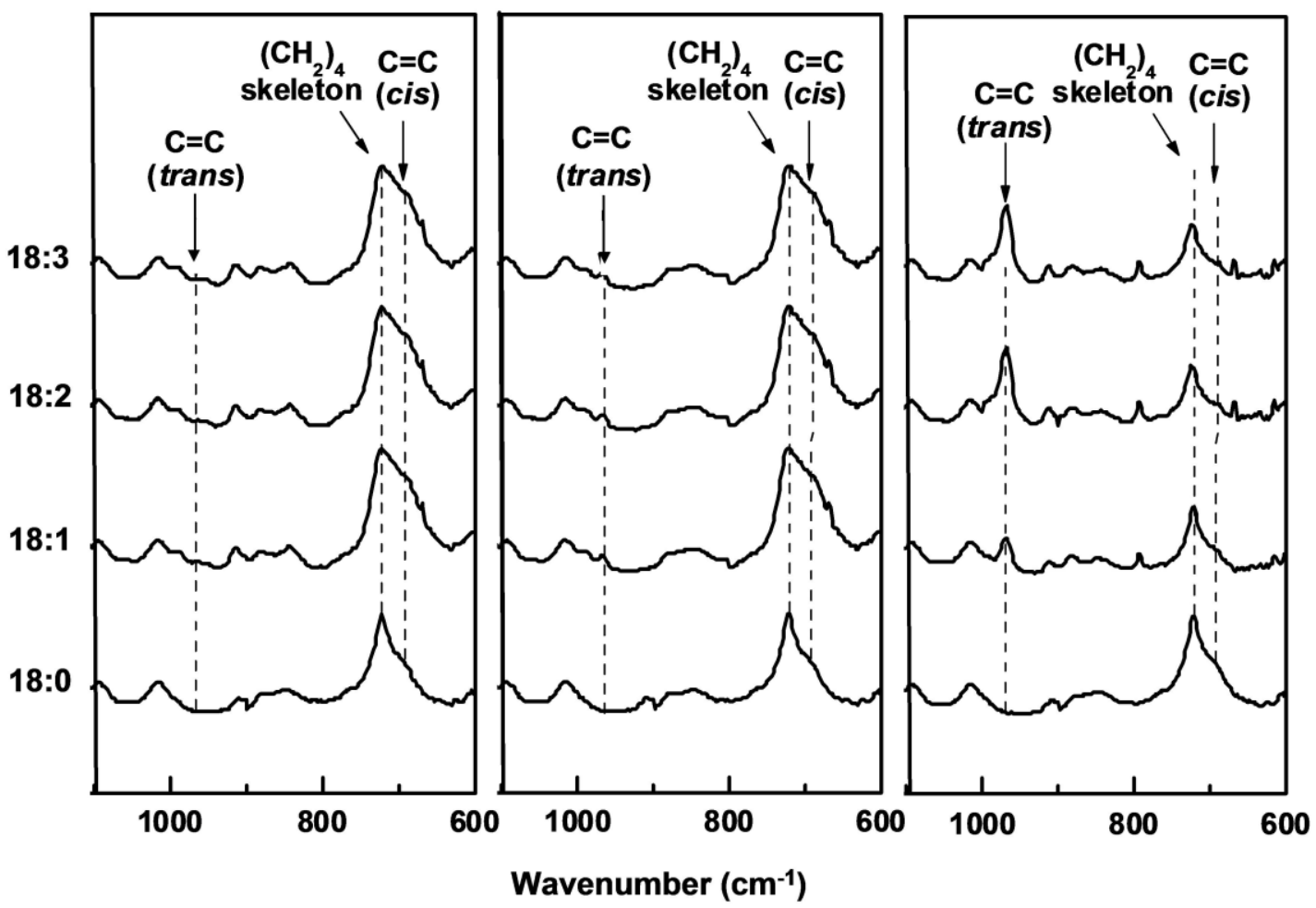

Fig. 5 FT-IR spectra of various FAME as treated in supercritical dimethyl carbonate method at different reaction conditions a) Untreated FAME, b) $300^{\circ} \mathrm{C} / 20 \mathrm{MPa} / 30 \mathrm{~min}$ and c) $380^{\circ} \mathrm{C} / 20 \mathrm{MPa} / 30 \mathrm{~min}$ 


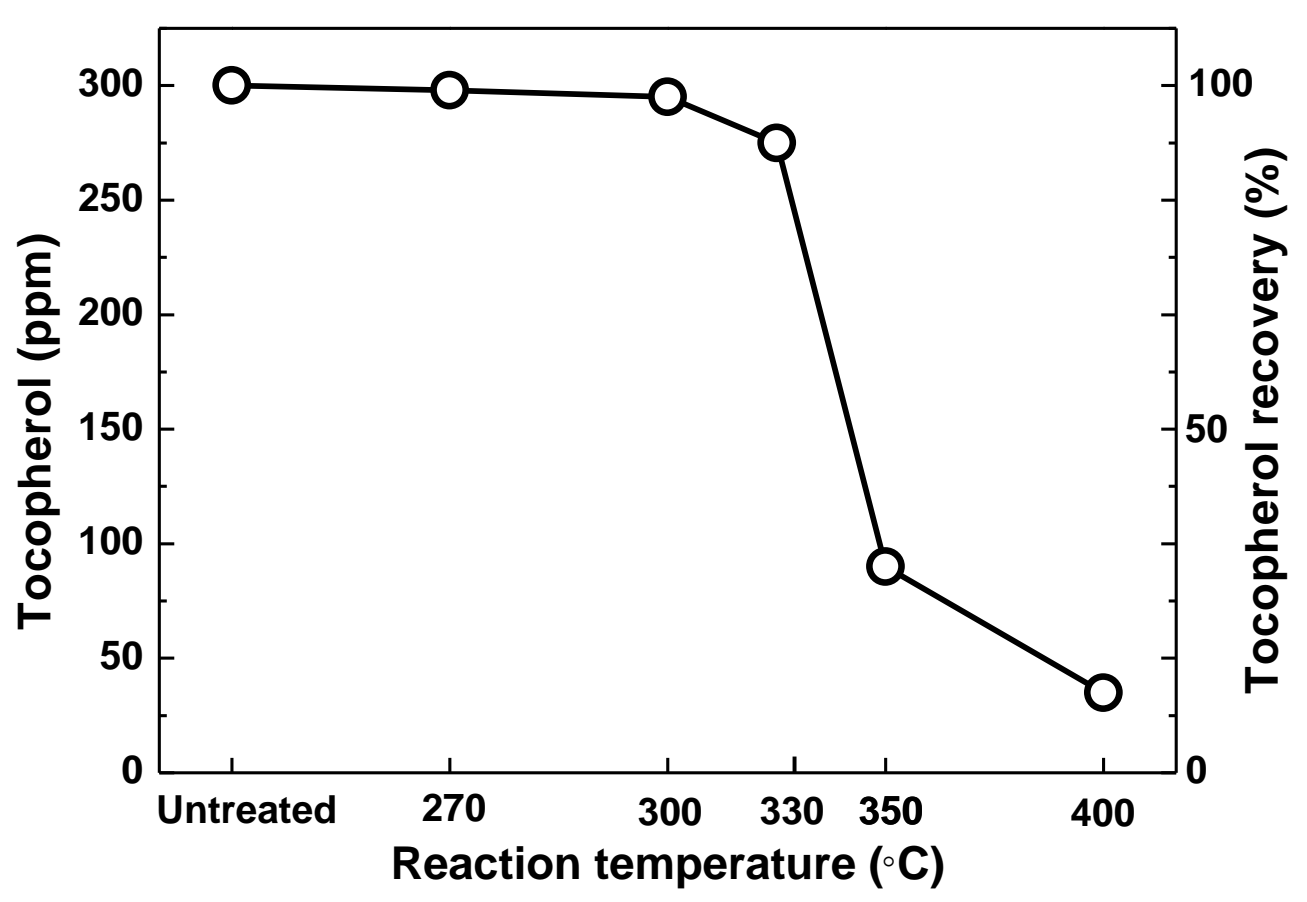

Fig. 6 Effect of temperature on tocopherol content in supercritical dimethyl carbonate method at $20 \mathrm{MPa}$ for $30 \mathrm{~min}$ 
Table 1 Total fatty acid composition of rapeseed oil used in this study

\begin{tabular}{lcc}
\hline${\text { Fatty } \text { acid }^{\mathrm{a}}}$ & Composition (wt\%) \\
\hline Palmitic acid & $16: 0$ & 6.0 \\
Stearic acid & $18: 0$ & 1.4 \\
Oleic acid & $18: 1$ & 57.6 \\
Linoleic acid & $18: 2$ & 23.8 \\
Linolenic acid & $18: 3$ & 11.2 \\
\hline a The former number represents the one of the carbons in the hydrocarbon chain while the \\
latter the number of the double bond in fatty acid
\end{tabular}


Table 2 Fuel properties of fatty acid methyl esters (FAME) from rapeseed oil as treated in supercritical dimethyl carbonate method compared with international standards

\begin{tabular}{|c|c|c|c|c|c|c|}
\hline \multirow[b]{2}{*}{ Properties } & \multirow[b]{2}{*}{ Method } & \multirow[b]{2}{*}{ Unit } & \multirow{2}{*}{$\begin{array}{c}\text { FAME } \\
\text { (Biodiesel) }\end{array}$} & \multicolumn{3}{|c|}{ International standards ${ }^{a}$} \\
\hline & & & & $\begin{array}{c}\text { Japan } \\
\text { (JIS K2390) }\end{array}$ & $\begin{array}{c}\text { EU } \\
(\text { EN 14214) }\end{array}$ & $\begin{array}{c}\text { US } \\
\text { (ASTM D6751-07) }\end{array}$ \\
\hline Kinematic viscosity $\left(40^{\circ} \mathrm{C}\right)$ & ASTM D445 & $\mathrm{mm}^{2} / \mathrm{s}$ & 4.3 & $3.5-5.0$ & $3.5-5.0$ & $1.9-6.0$ \\
\hline Carbon residue & ASTM D4530 & $w t \%$ & 0.08 & $\leq 0.30$ & $\leq 0.30$ & $\leq 0.05$ \\
\hline Pour point & ASTM D2500 & ${ }^{\circ} \mathrm{C}$ & -7.0 & - & - & - \\
\hline Cold filter plugging point & ASTM D6371 & ${ }^{\circ} \mathrm{C}$ & -7.2 & - & - & - \\
\hline Ignition point & ASTM D93 & ${ }^{\circ} \mathrm{C}$ & 162.5 & $\geq 120$ & $\geq 101$ & $\geq 130$ \\
\hline Cloud point & ASTM D6749 & ${ }^{\circ} \mathrm{C}$ & -7.0 & - & - & - \\
\hline Oxidation stability & EN 11442 & $\mathrm{~h}$ & 5.5 & - & $\geq 6$ & - \\
\hline Ester content & EN 14103 & $w t \%$ & 97.4 & $>96.5$ & $>96.5$ & - \\
\hline Monoglyceride & EN 14105 & $w t \%$ & 0.1 & $<0.80$ & $<0.80$ & - \\
\hline Diglyceride & EN 14105 & $w t \%$ & 0.06 & $<0.20$ & $<0.20$ & - \\
\hline Triglyceride & EN 14105 & $w t \%$ & n.d. ${ }^{b}$ & $<0.20$ & $<0.20$ & - \\
\hline Total glycerol content & EN 14105 & $w t \%$ & 0.02 & $<0.25$ & $<0.25$ & $<0.24$ \\
\hline Water content & EN ISO12937 & $\mathrm{mg} / \mathrm{kg}$ & 255 & $<500$ & $<500$ & $<500$ \\
\hline Acid number & EN 14104 & $\mathrm{mg}(\mathrm{KOH}) / \mathrm{g}$ & 0.14 & $<0.50$ & $<0.50$ & $<0.50$ \\
\hline lodine value & EN 14111 & $g\left(I_{2}\right) / 100 g$ & 102 & $<120$ & $<120$ & - \\
\hline
\end{tabular}

a JIS (2008); CEN (2003); ASTM (2007).

${ }^{b}$ n.d., not detectable. 